\title{
DUCTILITY CONSIDERATIONS IN SEISMIC DESIGN OF HIGH RISE BUILDINGS
}

\author{
G. H. F. McKenzie*
}

\section{$\underline{\text { Abstract }}$}

Design measures for providing earthquake resistance in high rise buildings are set out. It is essential that any building designed to code seismic coefficients should have adequate ductility, since its structure will be forced well into the yield range in a major earthquake.

Methods of assessing the ductility requirements in individual members of building frames are presented, together with procedures for determining the values of $\phi_{\mathrm{u}} / \phi_{\mathrm{y}}$ at individual hinge points, under seismic deflections into the plastic range. Conditions which give rise to large values of $\phi_{u} / \phi_{y}$ are pointed out. Design problems involved in the formation of column hinges are dealt with. Considerations affecting the use of dynamic analysis for elasto-plastic response in determining values of $\phi_{\mathrm{u}} / \phi_{\mathrm{y}}$ at hinges are pointed out. Design procedures for satisfying ductility demands in individual members are discussed.

\section{(1) Response of Elastic Systems}

It is well recognised that adequate ductility is an essential property of high rise earthquake resistant buildings. Fig. 1 shows the smoothed acceleration response spectra for elastic systems, for the 1940 El Centro Earthquake, N-S component. The curves show the response for $2 \%$ critical damping and $10 \%$ critical damping respectively. In the same figure, the graph of the New Zealand Zone A design coefficients for Public Buildings is drawn. The load factors and undercapacity factors which are used in the New Zealand concrete codes give minimum ratios of ultimate strength to design strength of 1.37 for beams and 1.79 for columns. Even after applying these values to the graph shown, it is obvious that the response movement of structures must go well beyond the elastic limit of deflection.

\section{(2) Elasto-Plastic Response}

Fig. 2 shows the idealised form of the load deflection graph of a simple reinforced concrete structure which is subjected to reversals of overload, producing deflections in each direction beyond the elastic limit. The initial elastic deflection is shown by the line $O A$, the point A representing the load and deflection corresponding to the elastic limit. The post eleastic portion of the load-deflection graph is represented by the horizontal line $A B$, passing through $A$, and the complete cycle is shown by the figure OABCDEA. $B C$ and $D E$ are considered to be parallel to $O A$, and $E B$ and $C D$ are horizontal. In the first half cycle, the area of the triangle FAO

* Assistant Chief Structural Engineer, N.Z. Ministry of Works. represents the energy which is stored elastically and passed to the next half cycle, while the area of the parallelogram ABPO represents the energy which is dissipated. Hence the ratio $\mathrm{FB} / \mathrm{FA}$ is directly related to the proportion of the energy fed in during one half cycle which is dissipated as a result of the post elastic movement. This ratio is called the ductility factor and designated by the symbol $\mu$, and is defined as the ratio of maximum displacement/elastic displacement.

\section{(3) Decrease in Response Due to Ductility}

The effect of post elastic behaviour in damping down seismic response is demonstrated by the solid line graphs in Fig. 3, which show the acceleration response spectra for $10 \%$ critical damping and different values of $\mu$, for the $1940 \mathrm{El}$ Centro Earthquake. (The graphs are drawn from information in Blume Newmark and Corning(1)). The decrease in response with increase in $\mu$ is clearly shown. For reasons that will be made clear later in this paper, the highest overall value of $\mu$ which can be obtained in most structures is 4 , and in some structures a lower value has to be accepted. The New Zealand seismic design code is based on $\mu=4$.

\section{(4) Equal Deflection Rule and Reduction Factors}

It is found that the spectral displacement for an elasto-plastic system is approximately the same as that for an elastic system having the same period of vibration. In other words, referring to Fig. 4, if ab is the graph of response for an elastic system, ade' would be the approximate graph of response for an elastoplastic system, with $e^{\prime}$ lying on the vertical line bf. This rule will be used later in the paper to show various effects.

Referring to rig. 4, it can be shown that $\frac{c e^{\prime}}{c d}=\frac{f b}{f e^{r}}$

or, in other words,

$$
\mu=\frac{\text { base shear for elastic system }}{\text { base shear for elasto-plastic system }}
$$

Thus it can be said that the numerical value for the elasto-plastic reduction factor applied to elastic base shear is approximately equal to the ductility factor. However, it must be remembered that the two factors are fundamentally different, one being a ratio of deflections while the other is a ratio of base shears. 


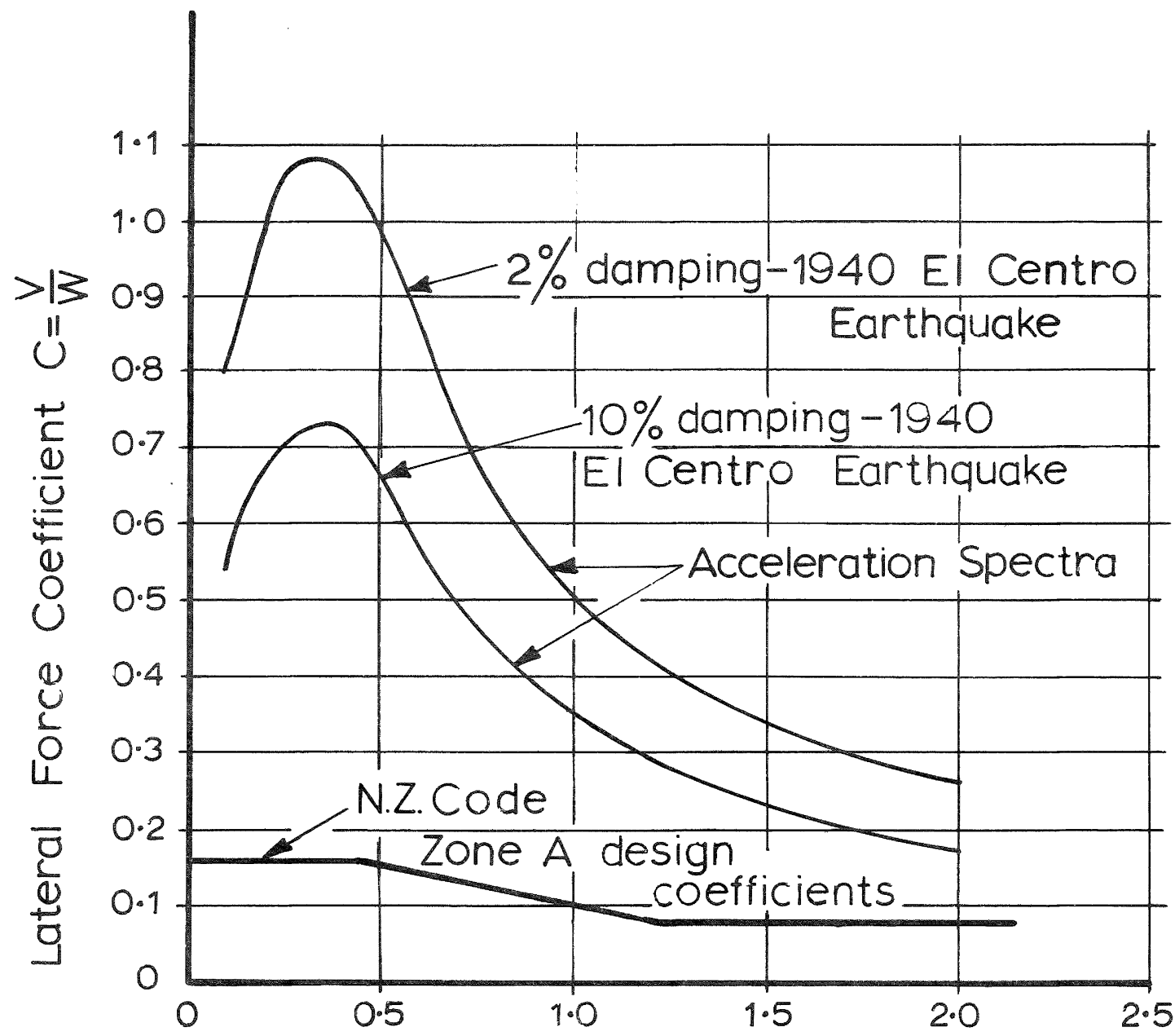

Fig. 1. Undamped Natural Period in Seconds

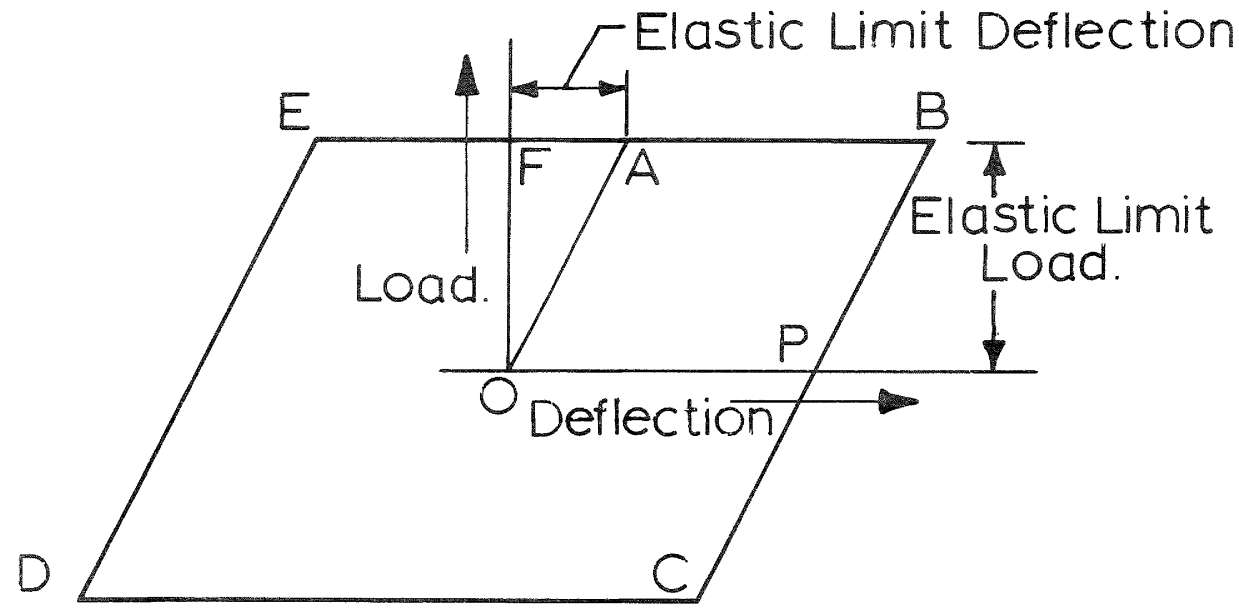

Fig. 2. Elasto Plastic Response 


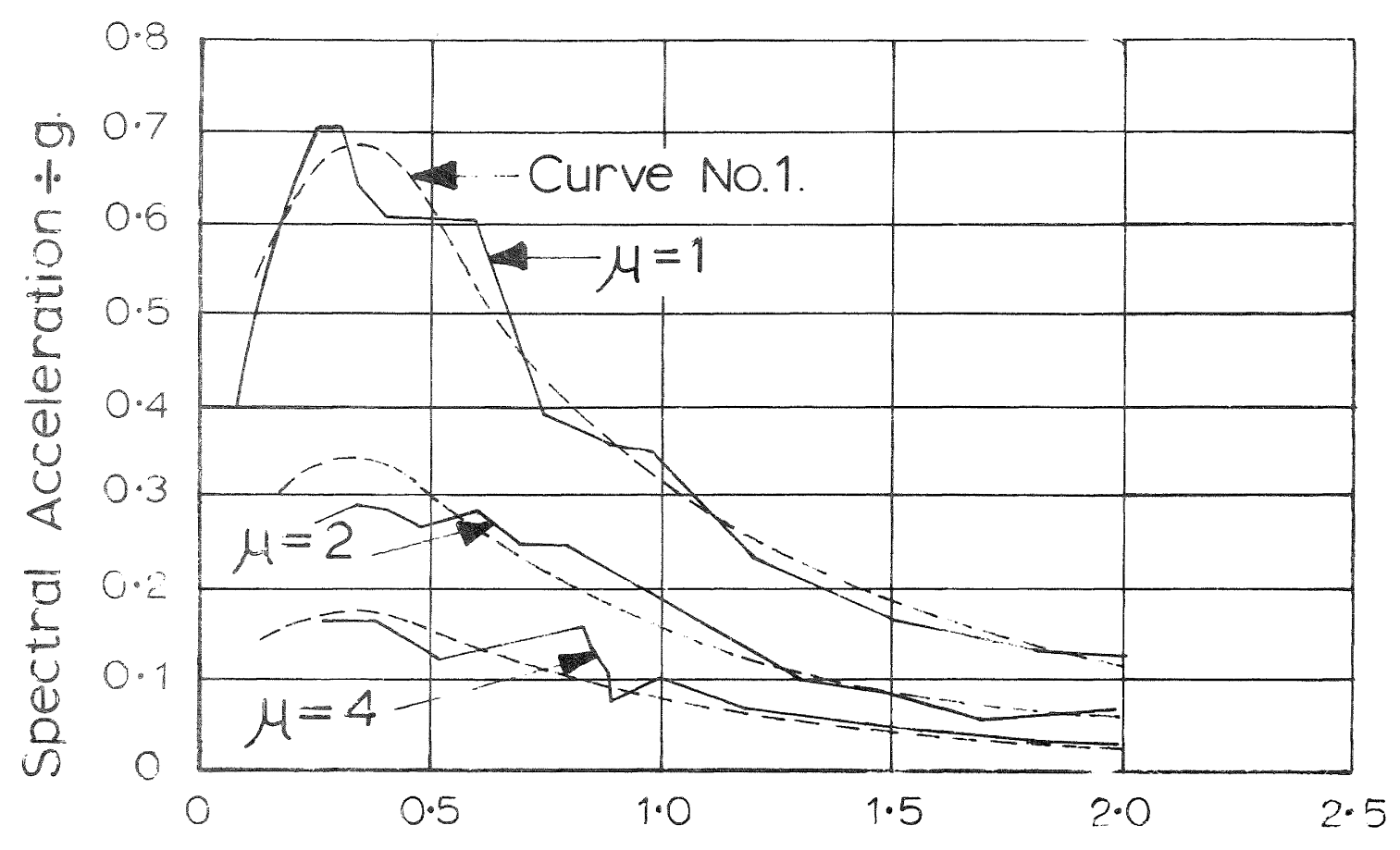

Fig. 3. Natural Period in Seconds.

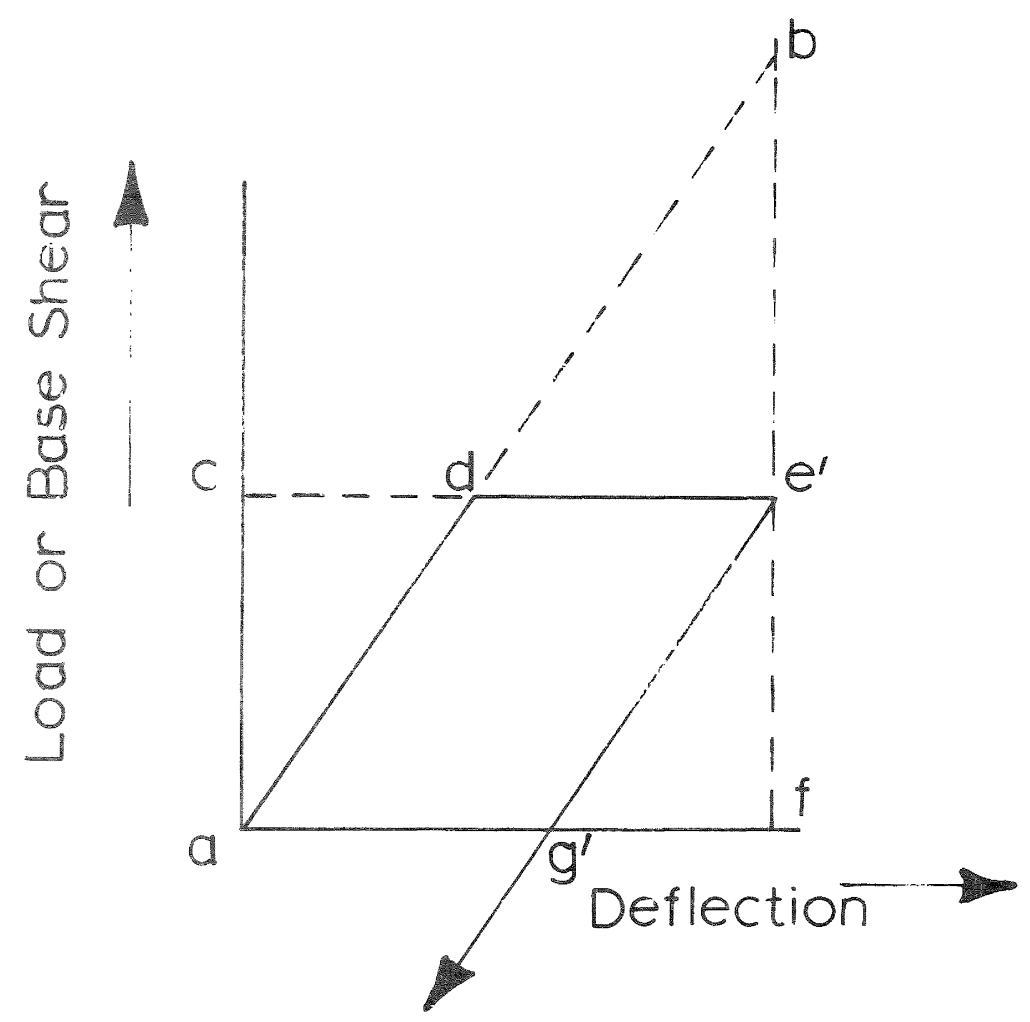

Fig. 4. 
Comonstrated by the dotted curves in Fig. 3. Irve Noc 1 j.s a smooth curve drawn through the sponse graph for $\mu=1$. The two other dotted curves are drawn with ordinates equal to $\frac{1}{2}$ and $\frac{1}{4}$ rospectively of curve No. 1. They generally correspond closely to the graphs for $\mu=2$ and $\mu=4$ respectively.

The following demonstrates the extent to which the numerical correspondence of ductility ractor and reduction factor depends on the form of the earthquake. If the applied earthquake consisted of the extreme case of only one very large pulse (a lype which has never been recorded) the reduction ractor for undamped systems would be siven by

$$
R=\frac{1}{\sqrt{2(\mu-1)}}
$$

where $R=\frac{\text { elasto-plastic response acceleration }}{\text { lastionesponse }}$

How was built up over several cycles by a succession of strong input ground pulses in phase with the vibrating structure, the value of $R$ would drop. It is obvious that the rule of numerical correspondence is not an exact one, and should be used to show effects rather than precise numerical values. This is the use to which it will be put later in this paper.

\section{5) Relationship Between Ductility Factor and Strain Factor}

In deflecting into the plastic range, a member will usually develop a plastic hinge over a short portion of its length, at the position at maximum moment. Very severe flexural strains are developed in the plastic hinge area, and it is the magnitude of these which usually limits the ductility ractor that any single member can develop. The ratio ultimate strain/elastic strain for the hinge area is measured by the ratio

$$
\frac{\phi_{u}}{p_{y}}
$$

where $\phi_{u}$ is the hinge curvature at ultimate deflection

and $\phi$ is the hinge curvature at elastjc derlection limit

Hence it is important to determine the relationship between $\mu$ and $\phi_{u}$

$$
\frac{\phi_{u}}{\phi_{y}}
$$

For a single cantilever subjected to a triangular distribution of bending moment, it can be proved that

$$
\frac{\phi_{u}}{\phi_{y}}=\frac{\mu-(1-n)^{3}}{1-(1-n)^{3}}
$$

where $n=$ Length of hinge length of single cantilever

Hence, for a ductility ractor of 4 ,

$$
\frac{\phi_{u}}{\phi_{y}}=\frac{12.1 \text { for } n=\frac{1}{10}}{7.2 \text { for } n=\frac{1}{5}}
$$

The above relationship can be applied to any portion of a flexural member.. which is subjected to a triangular bending moment distribution. Most members of a seismic frame can be dealt with on this basis, by dividing each beam or column into two single cantilevers, each extending from a joint to a point of inflection.

Expressions for calculating the length of a hinge are given by Baker (2) and Mattock (4).

\section{(6 Relationship Between Overall Frame Ductility and Individual Member}

It is obvious from previous parts of this paper that it is essential to determine the overall ductility of a structure. If the seismic design coefficients have been derived from the assumption of a ductility factor of 4 , it is essential to ensure that a structure can develop this ductility factor. Again, it is obvious that a design base shear coefficient on i.ts own does not define the seismic capacity of a structure. It is necessary to know the design base shear plus the ductility factor in order to assess the general seismic performance of a structure of a given natural period.

Assume that design seismic load is applied to a structure, and is then gradually increased until sufficient plastic hinges are formed to prevent any further increase in seismic resistance in the structure. The deflection of the structure is then increased by means of further rotation of all plastic hinges, without any further increase in load. The question arises as to what is the overall ductility factor of the structure. It can obviously not be answered in the general case purely on deflection considerations, because all members will have different loads, some members will remain elastic while others will develop plastic hinges and the plastic hinges in the most general case will not all form simultaneously. The method advocated by the writer is to use a strain energy concept.

Referring to Fig. 5(a), if the load-deflection graph represents a simple member having a ductility factor of 4 , the area ABE, donoted by $a$, represents the elastic strain energy, while the area $b$ represents the inelastic strain energy at the end of one half cycle. Then if the ductility factor $=4, a=\frac{1}{6} b$, and $\frac{1}{7}$ of the energy fed into the member in the half cycle is retained as elastic energy.

In any more complex system, such as a frame, if $\frac{1}{7}$ of the energy fed into it in a half cycle is retained as elastic energy, the system will have exactly the same base shear response characteristics as the simple member with $\mathscr{H}=4$. Hence, in such a case, the overall ductility factor of the complex system can be said to be 4 .

Figs. 5(b) to (e) show load-deflection graphs for typical members in a frame. 5(b) shows a lightly loaded member which remains elastic, while $5(\mathrm{c})$ shows a more heavily loaded member which remains elastic. Fig。 5(d) shows a member which develops a plastic hinge early in the process of load increase, while Fig. $5(e)$ shows a member which developes a plastic hinge later. The area marked a in each graph represents elastic energy, while the area marked b in each graph represents inelastic 
energy. Then, from the argument in the previous paragraph, if

$$
\Sigma a=\frac{1}{6} \Sigma b
$$

then the overall ductility factor $=4$.

Alternately if $\sum a=\frac{1}{2} \sum b$

then the overall ductility factor $=2$ 。

This method is extremely general in its application. The individual load-deflection graphs can represent individual members or single storeys or other sub assemblages of members. It is an extremely useful tool to a designer, because it shows very quickly, in a simple visual manner, the effect of changing member properties。 For instance, in graph $5(\mathrm{c})$, the effect of stiffening the member on area a can be seen. Examples of its application will be shown later in the paper.

\section{(7) Ductility of Ordinary Building Frames Where}

Hinges are Developed in All Beams

Consider the structure shown in Fig. 6(a) to be deflected into the inelastic range under the action of lateral seismic load. Assume that hinges are formed in all beams, at the points indicated by dots. Next consider separately the portion of the frame contained by the three dotted lines, which are positioned to pass through the points of inflection of the column and the beam. This sub-assembly consists of 3 single cantilevers, with their "fixed" ends joined together. The horizontal deflection $\Delta u$ of the lower of the two column points of inflection, from a vertical line passing through the beam-to-column joint can be considered as the sum of the following 3 deflections, which are shown diagrammatically in Figs. 6(b), 6(c) and $6(d)$ 。

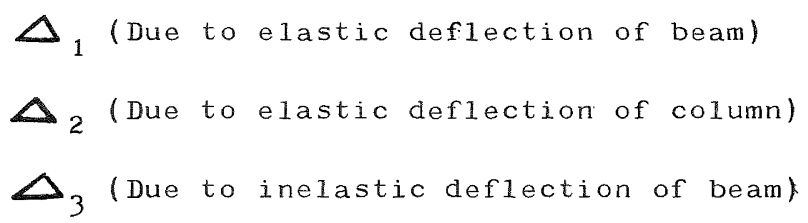

Assume $\mathrm{S}$ is the shear at the column level being considered, and let the respective strain energies due to the 3 components above be respectively $U_{1}, U_{2}$ and $U_{3}, U_{3}$ being inelastic.

Then $U_{1}=\frac{\Delta_{1} S}{2}, U_{2}=\frac{\Delta_{2} S}{2}$ and $U_{3}=\Delta_{3} s$

The whole structure can be broken up into similar sub-assemblages, and, if the effect of the lower portion of the ground storey column is neglected, the following relationship holds。

$$
\begin{aligned}
& \text { If, for the structure as a whole, } \mu=4 \\
& \text { Then } \sum U_{3}=6\left(\sum U_{2}+\sum U_{1}\right) \\
& \text { For } \mu=2, \sum U_{3}=2\left(\sum U_{2}+\sum U_{1}\right)
\end{aligned}
$$

Corresponding relationships hold for other values of $\mu$. The effect of the bottom portion of the ground storey column can be taken into account by including its elastic and inelastic energy areas in the above expressions.

The ductility factor for each beam is equal to $\frac{\Delta_{3}}{\Delta_{1}}$, and the corresponding $\frac{\phi_{\mathrm{u}}}{\phi_{\mathrm{y}}}$ for each beam hinge rotation demand can be calculated by the procedure set out in section (5).

Quite often, it will be sufficient to simply take typical assemblages near the top of a building and near the bottom of a building. The beam hinge demands can be checked in each case for a ductility factor of 4 in the assemblage, when considered as a structure on its own. However, in averaging out, it must be remembered that members near the bottom have a greater effect on overall ductility factor than those at the top, because the heights of figures are greater and hence areas are greater。

\section{(8) Factors Causing Severe Hinging Conditions}

The important effects, on $\phi_{u}$ hinge demands, $\phi_{y}$

of column stiffness ratio are shown by calculationsam stiffness

$$
\frac{\phi_{\mathrm{u}}}{\phi_{\mathrm{y}}} \text { demands for } \frac{\text { overall ductility factor of }}{4}
$$

\begin{tabular}{|l|c|lc|}
\hline$\frac{\Delta_{2}}{\Delta_{1}}$ & $\begin{array}{c}\text { Beam Ductility } \\
\text { Factor }\end{array}$ & $\frac{\phi_{u}}{\phi_{\mathrm{y}}}$ for beam hinge \\
\cline { 2 - 4 } & & $\mathrm{N}=\frac{1}{5}$ & $\mathrm{~N}=\frac{1}{10}$ \\
\hline 0 & 4 & 7.2 & 12.1 \\
0.25 & 4.75 & 9.0 & 15.1 \\
0.50 & 5.5 & 10.2 & 17.6 \\
1.0 & 7 & 13.3 & 23.1 \\
2.0 & 10 & 19.4 & 34.1 \\
\hline
\end{tabular}

This effect is one which is overlooked by designers when they use design codes as criteria for detailing ductile seismic frames. The point is that design codes such as the 1966 SEAOC Lateral Force Requirements are expected to give adequate ductility in the type of office building where $\frac{\Delta_{2}}{\Delta_{1}}$ is small and the corresponding $\frac{\phi_{u}}{\phi_{\mathrm{y}}}$

is moderate. Designers, therefore, should be on their guard when dealing with structures of unusual proportions。 It should also be remembered that the table above gives $\phi_{u}$ for the

$$
\overline{\phi_{\mathrm{y}}}
$$

most favourable circumstances, i.e. When hinges form simultaneously in all beams. If some beams do not form plastic hinges (for example very long spans), or if some beams form hinges later than others in the deflection cycle, some beams will have to develop appreciably higher values of $\phi_{\mathrm{u}}$. When there is any doubt, the

$$
\phi_{y}
$$

strain energy approach advocated by the writer in section (6) should be used to check the hinging demands, for a static loading pattern similar to the design loading.

In formulating the 1966 SEAOC Requirements, consideration was given to tests carried out by Hanson and Connor $(5)$. If is, therefore, 

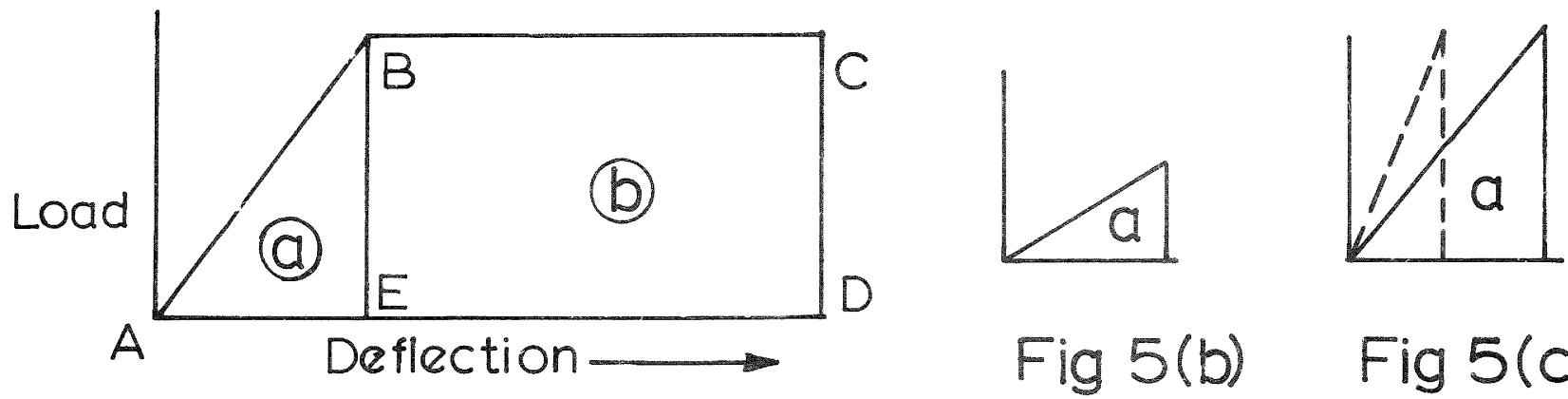

Fig 5(b) Fig 5(c)

Fig 5 (a)

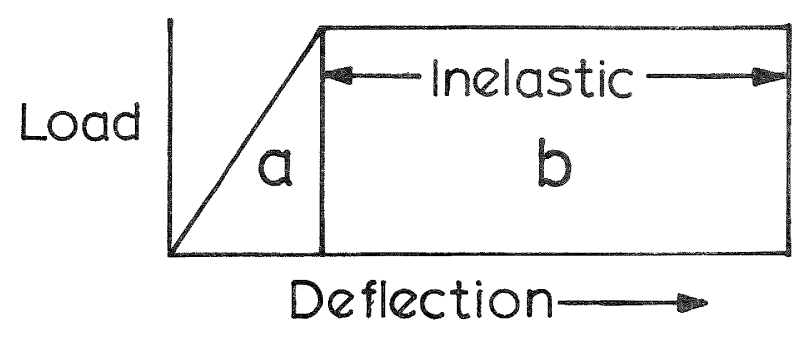

Fig 5(d)

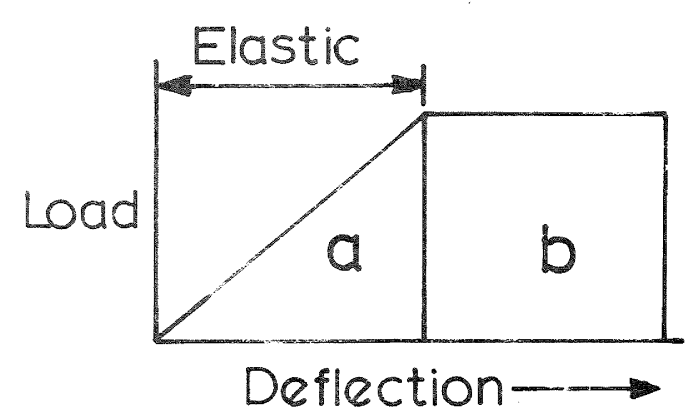

Fig 5(e)
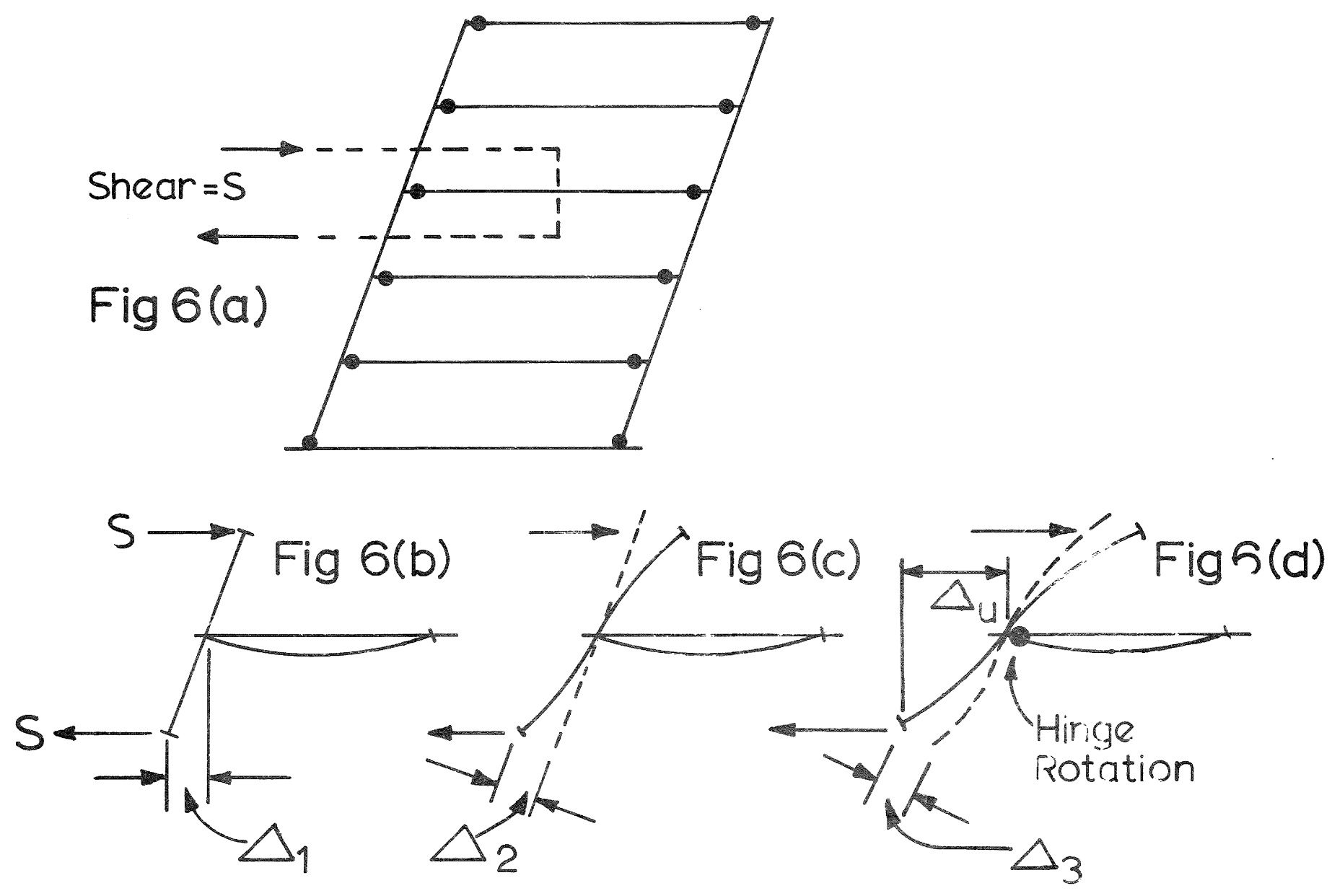
228

of interest to compare the value of the beam $\phi_{u}$ calculated for the assemblage used in the $\bar{\phi}_{\mathrm{y}}$ tests, with the table above. The beam ductility factor, for the value of $\mu=5$ used in the tests, is approximately 7.05 , and the corresponding value of $\phi_{\mathrm{u}}$ is approximately 18.2 $\frac{\psi_{y}}{y}$

The writer considers that, at the present state of knowledge, the design value for $\phi_{u}$, in reinforced concrete beams designed to $\phi_{\mathrm{y}}$ withstand seismic hinging, should be

Iimited to a maximum of 15 , and, if possible, should be kept below 13.

\section{Frames Where an Overall Ductility Factor of 4}

\section{Can Not Be Developed}

It is fairly obvious from the above that it does require careful design to achieve an overall ductility factor of 4 . In buildings which, for one reason or another, develop plastic hinges in only a small proportion of the members a ductility factor of 4 can not be achieved. The question arises as to whether it is sound practice to accept a lower ductility factor and compensate by requiring an appreciably higher base shear design coefficient.

For example, a building structure with a period of 0.45 seconds and having $10 \%$ critical damping would require a base shear coefficient of $0.16 \mathrm{~g}$ together with a ductility factor of 4 to resist the $1940 \mathrm{EI}$ Centro earthquake. If we refer to Fig. 3, we find that the same structure with a ductility factor of 2 would require a yield strength of approximate $1 \mathrm{y} 0.30 \mathrm{~g}$ for the El Centro earthquake.

Hence a designer may think it reasonable to design for a seismic coefficient of $0.30 \mathrm{~g}$ and accept a ductility factor of 2. In the writer's opinion, this approach requires caution, because it gives less margin for coping with earthquakes greater than the design one.

Referring to Fig. 7, assume that $a b$ is the load deflection graph for the elastic spectral response to the design earthquake. Then, assuming the equal deflection rule is applicable, (as set out in section (4))

ade is the elastoplastic response for $\mu=4$ ade' is the elastoplastic response for $\mu=2$

Assume a greater earthquake now comes, and elastic response is increased by $25 \%$, as shown by the line af. Then, using the equal deflection rule again, the two elasto-plastic systems are represented by the graphs adh and ad'h'. It is apparent that the larger earthquake has the following effects on the two systems。

System designed for $\mu=2$; plastic range movesystem designed for $\mu=4$; plastic range movement increased by $33 \frac{1}{3} \%$

Hinge rotations are approximately proportional to plastic range movements. Hence, the system with $\mu=4$ can cope with the larger earthquake with only $\frac{2}{3}$ of the increase in hinge rotations required by system with $\mu=2$ 。 Hence, it is advisable to limit the design values of $\phi_{\mathrm{u}}$ to lower values for $\mu=2$ than $\frac{\psi}{y}$

those recommended for $\mu=4$.
(10) Example of Building Designed for a Ductility Factor of 2

An example of reducing the ductility factor is shown by the building in Figs。 8 to 10. Because of requirements of the occupancy, the ground storey is high, with comparatively slender columns. The upper storeys are much stiffer than the ground storey, and the beams are appreciably stronger than the columns. The result is that, under seismic loading, the only members which develop plastic hinges are the bottom storey columns, and the deflected shape is as shown by the line diagram Fig. 9.

The $\phi_{\mathrm{u}}$ values for the column hinges can $\bar{\phi}_{\mathrm{y}}$

be calculated by a very simple application of the strain energy principle already described in section (6). Load-deflection graphs are drawn for the horizontal interstorey deflection in each storey - i.e. the movement of each floor with respect to the floor below. The loading system used is the design distribution of seismic loading, increased up to the level at which hinges develop in the ground storey columns. Then, the load deflection graphs for the respective storeys are as shown in Fig. 10. For the overall ductility factor to be 4 , the following relationship would have to hold. The inelastic area (b) of the ground storey graph would have to be 6 times the sum of (elastic area (a) of the ground storey graph plus the areas of the graphs for all the upper storeys). This would require a high value of $\phi_{u}$ in the

$$
\overline{\phi_{\mathrm{y}}}
$$

column hinges. Area calculations show the following results, for rotations of column hinges.

If overall value of $\mu=4, \frac{\phi_{u}}{\phi_{y}}=20.5$ in columns

If overall value of $\mu=2, \frac{\phi_{\mathrm{u}}}{\phi_{\mathrm{y}}}=9.0$ in columns

The value of 20.5 is too high even for structural steel. On the other hand, the value of 9.0 can be sustained by reinforced concrete columns, provided that certain criteria, mentioned later in this paper, are satisfied. Note also that the writer has some further reservations, mentioned later in the paper, on the general principle of allowing hinges to develop in reinforced concrete columns.

\section{(11) Frames Which Develop Hinges in Columns}

\section{Under Lateral Load}

One of the main disadvantages of frames which develop hinges in columns under lateral load has been pointed out by Park(6). This is that, if the columns in any storey develop hinges at top and bottom, they prevent hinges developing subsequently in any of the stories above that level. This drastically reduces the number of stories that can dissipate inelastic energy. The worst case occurs when the lowest storey develops column hinges before any other stories can. None of the storeys above can subsequently develop hinges, and hence a ductility condition similar to that of the building described in section (10) results. Referring back to the strain energy concept of section (6), the inelastic strain 


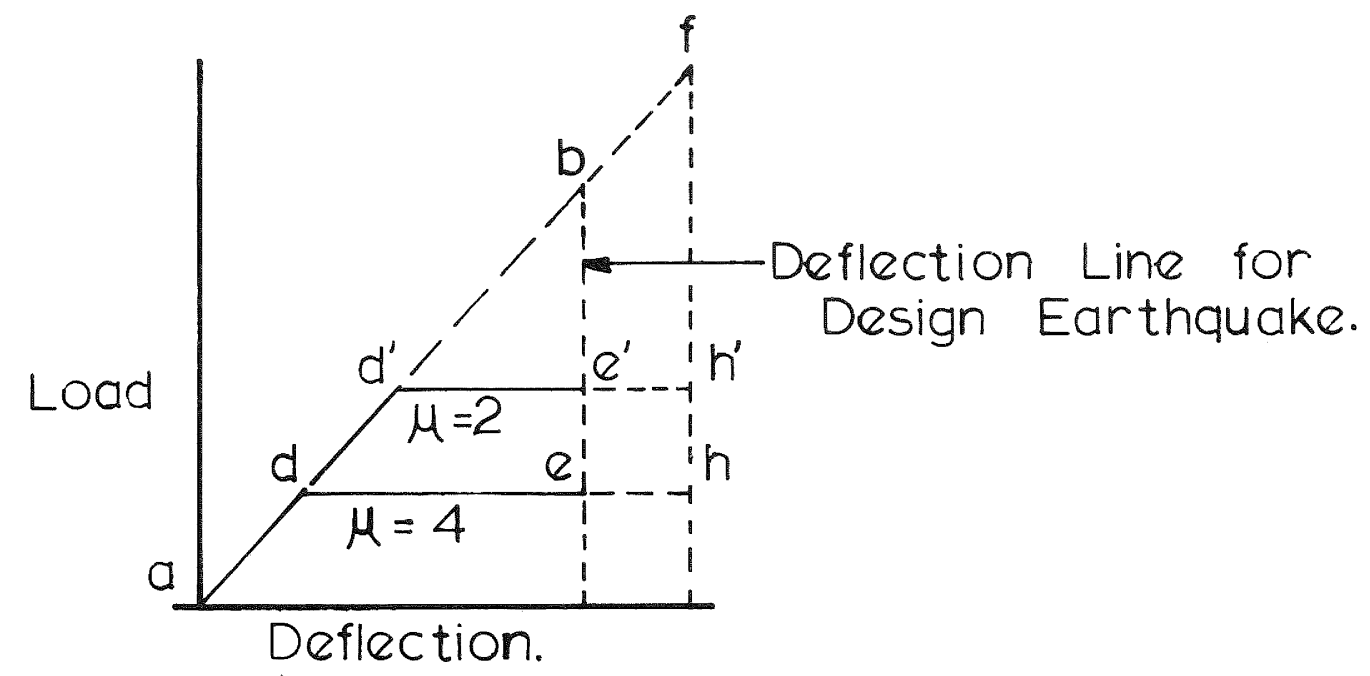

Fig 7 Effect of $\mu$ Value on Response to Earthquake Greater than the Design Earthquake.

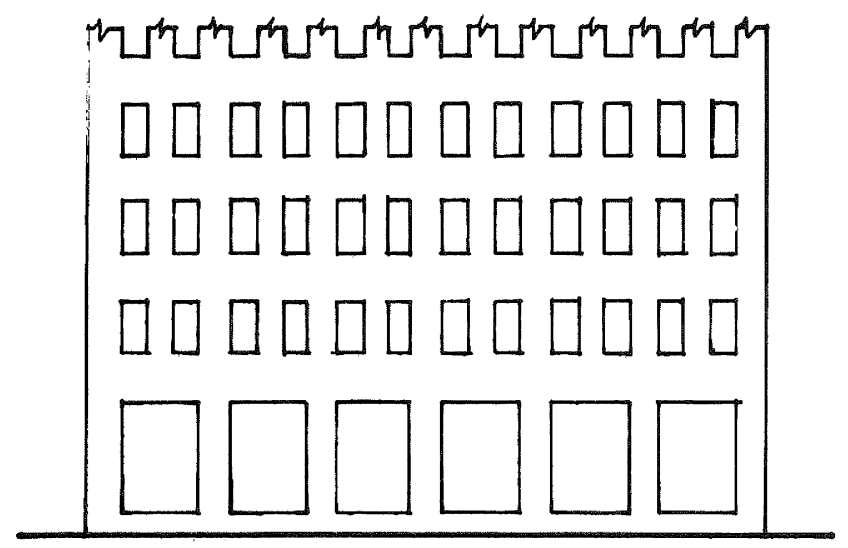

Fig 8 Lateral Frame.

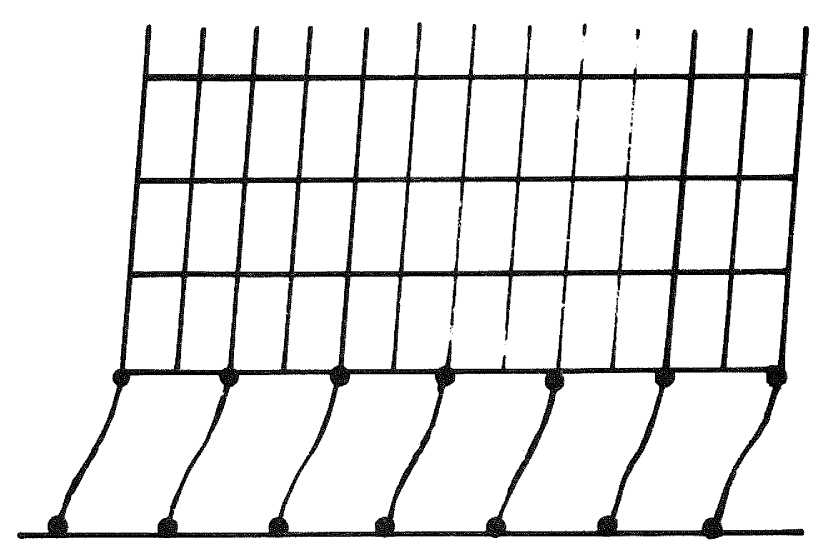

Fig 9 Deflected Shape.
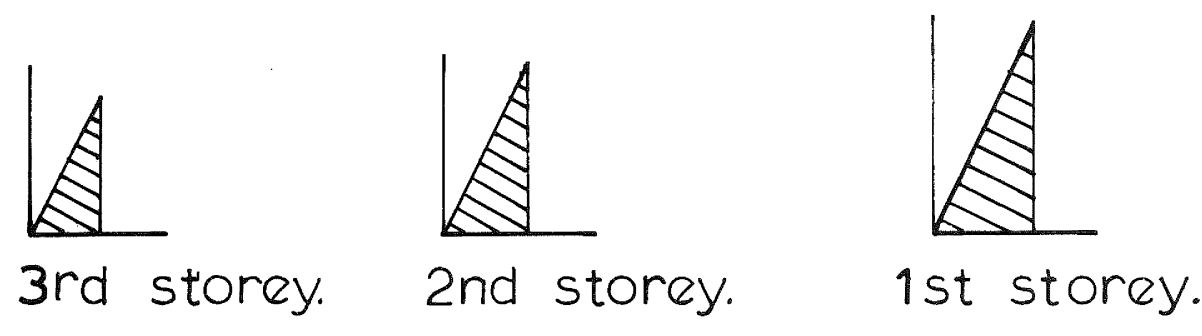

Fig 10 -Load-Deflection Curves for Individual Storeys.

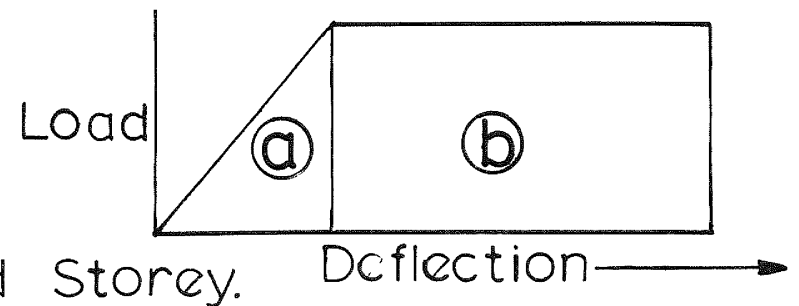


energy in the bottom storey alone has to balance the sum of the elastic strain energy in all storeys. This will result in very high hinging demands in the bottom storey columns. Even if a very much reduced ductility factor for the building as a whole is adopted, the values of $\phi_{u}$ in the bottom storey columns may $\frac{\phi_{y}}{\phi_{y}}$

still be too high.

The ideal answer is obviously to make columns stronger than beams at all joints. However, this is not always possible-for example the need for long beam spans or for deep spandrel beams on exterior walls may make it impractical to make columns stronger than beams throughout.

If the problem of hinges forming in columns applies to only one or two stories of a building, a fairly safe solution to the problem can generally be found by making these stories appreciably stronger in relation to lateral design load then the other stories of the building. This will ensure that hinges form in all the other stories of the building before the column hinges form. In all cases where this is done, it is essential that the $\phi_{\mathrm{u}}$ values for

$$
\phi_{y}
$$

individual members should be checked by the strain energy procedures set down in section (6). This is because the unbalance in storey strengths will tend to increase the hinging demands in some members, and also because the hinging capacity in columns is limited and hence the column rotations need to be carefully controlied.

The condition where columns in all storeys are weaker than the beams is more difficult. In a 3 storied building with long spans, the writer has tackled this problem by progressively increasing the ratio of lateral storey strength design storey 1 oad, in passing from each storey to the next one down. For example, the top storey could be designed for design load $x$ load factor, the next one down for design load $\times 1.15 \times$ load factor and the next one down for design load $x 1.30 \times 1 . f$. As seismic response increased, hinges could be expected to form first in the top storey and then progressively down the building in all the other stories. This basis of design can obviously be used only in buildings with a small number of stories. Once again, the values of $\phi_{u}$ should be checked in individual members, by the strain energy method of $\bar{\phi}_{y}$ section (6). because of the possibility of unbalance in hinging demands, and because of the limited hinge rotation capacity of columns.

Even in the typical case where hinges are developed in a 11 beams, as shown in Fig. 6(a), it is obvious that a hinge would form at the bottom of each ground storey column. This form of hinging does not prevent hinges from forming in other stories, so it does not have the objections of the other forms discussed. However, it still gives reason for concern, in view of the limited $\phi_{u}$ capacity of reinforced

$$
\frac{\phi_{y}}{\phi_{y}}
$$

concrete columns, and consequently the $\phi_{\mathrm{u}}$

value for this hinge, resulting from $\bar{\phi}$

the overall ductility factor assumed, should be calculated.

\section{(12) Hinge Rotation Capacity of Reinforced Concrete Columns}

In all cases where an appreciable value of $\phi_{u}$ is developed at column hinges, it is essent $\frac{\mathrm{u}}{\phi_{\mathrm{y}}}$

ial to be able to assess the column capacity in this respect. Recommendations for limiting values for beam hinges have been given at the end of section( 8 ), but the limiting values for column hinges are lower and are affected by other parameters such as axial load. There is practically no test data on the hinging capacity of reinforced concrete columns of the size used in the lower storeys of high rise buildings, and the only experimental evidence which the writer has seen published has been on small laboratory test pieces. A theoretical basis for assessing $\phi_{u}$ capacity of columns has been

$$
\frac{u}{y}
$$

given by Blume et al (1), and the writer recommends the use of this approach in the meantime, but it should be applied conservatively in the absence of adequate experimental data.

In Blume, Newmark and Corning(1) section 5.4 deals with this question, and the associated Fig. 5-16 gives the theoretical variation in $\phi_{\mathrm{u}}$ with change in axial load. It will be noted $\overline{\phi_{y}}$

that, for a $\phi_{u}$ of 9.0 (required for the building $\overline{\phi_{\mathrm{y}}}$

described in section (10) of this paper, to give an overall value of 2 for $\mu$ ), the column axial load has to be limited to $19 \%$ of the ultimate axial load, which is a fairly onerous restriction on the design of a high rise building. If the column load rises to $25 \%$ of ultimate axial load capacity, then the $\phi_{\mathrm{u}}$ capacity drops to 5. Admittedly the $\frac{\phi_{y}}{4}$ longitudinal steel percentage in the column of figure $5-16$ is high, at $5 \%$ of gross area, and a lower steel percentage will give rather higher values of $\phi_{u}$ capacity. (The correspond-

$$
\overline{\phi_{y}}
$$

ing curve for lower steel percentages can be calculated from Fig. 5-17 in Blume et al.) Against this, however, the assumed stress strain curve for concrete, on which Fig. 5-16 is based, is shown in Fig. 5-15, and this curve assumes that (a) confined concrete can be subjected to a maximum strain of 0.01 and (b) by inference that rectangular tied columns can be reinforced to give this degree of confinement in the core. Neither of these assumptions have been proved by test for the dimensions and detailing used in large rectangular tied columns, as designed for the lower stories of high rise buildings. Hence, a safety margin for the present state of knowledge should be applied to the theoretical curves, and the writer thinks that the prudent designer should keep values of $\phi_{u}$ in columns below 10. Even $\phi_{y}$

for these values, the limitation of axial load and the longitudinal steel percentage should be kept below the appropriate limits derived from the theoretical approach of Blume et al.

It should be remembered, incidentally, that if a hinge in a lower storey column is grossly weakened by excessive rotation, to the extent that it can no longer safely carry its heavy permanent axial load, it may be almost impossible to repair, because it is usually 
out of the question to temporarily remote the axial load. On the other hand, if a beam hinge is weakened by excessive rotation, it can more easily be repaired, by propping the beam on either side of the hinge, and cutting out and replacing the damaged concrete (and reinforcement also, if neeessary). This is an additional reason why column hinges must be designed on a much more conservative basis.

\section{(13) Dynamic Analysis for Elasto-Plastic Response}

A dymamic analysis that will give inelastic response is an essential procedure for the design of important buildings or buildings with unusual features. If high hinging demands in some members result from lack of balance in member strengths or unfavourable stiffness ratios, or if there is any reason to expect high hinging demands in some members arising in the higher modes of vibration, a dynamic analysis should be carried out. The dynamic analysis method must obviously be one from which the $\phi_{\mathrm{u}}$ values for individual member hinges can be $\sigma_{y}$ calculated.

The dynamic analysis is complementary to the strain energy procedure which was lescribed in section (6) for determining the individual values of $\phi_{u}$ corresponding to a given overall

$$
\frac{\mathrm{d}}{\mathrm{y}}
$$

value of $\mu$ for the frame. The strain energy procedure is more of a tool for design (as compared with analysis) in that a designer can see at a glance what will be the approximate effect of changing stiffness or strengths of different members on the hinge rotations at different points in the frame or on the overall frame ductility factor Again, the dynamic analysis gives the response to a particular earthquake, (or several selected earthquakes) while the strain energy procedure gives a more general result; namely the overall ductility factor corresponding to limiting values of $\phi_{u}$. The overall ductility factor can be considered as an absolute parameter of earthquake resistance, for assessing the general seismic performance of the structure. On the other hand, the dynamic analysis has the advantage of showing higher mode effects and does give an exact distribution of seismic response up the height of the structure for the particular earthquake record which is being applied.

\section{Necessity to Apply Load Factors to Earthquake used}

\section{for Dynamic Analysis}

It must be remembered that designers apply multiplying factors such as load factors to their design loads, as a very necessary safety measure to obtain final member strengths. Hence, any analysis results which are used in design must incorporate these load factors. It is accepted that the static strength of a reinforced concrete member must be equal to $1.25(D+L+E)$ and that $\phi=0.90$ for beams.

In other words, the final member strength must be based on $\frac{1.25}{0.9}(D+L+E)$

$$
=1.37(D+L+E) \ldots . .\left(R_{1}\right)
$$

To be consistent with this, the dynamic analysis must also be carried out for 1.37 $(D+L+E)$. In other words, the values of $D$ $+\mathrm{L}$ and the applied earthquake must be scaled up by 1.37 before being applied to the final structure. The structure with hinge Ou values

$$
\mathrm{O}_{\mathrm{y}}
$$

designed on these results will then have a safety factor of 1.37 on the required dynainic resistance for the combined loading.

Although this last requirement appears fundamental, it is surprising to see tho numbor of elasto-plastic dynamic responso investigations published where the earthquake applied to the final designed structure has been the actual record without any scaling factor. Thrse have naturally shown indiridual momber "xcursions into the plastic range which are far too low. The following calculations will make the point clearer.

From the relationship above marked $R_{1}$, it is apparent that the earthiuake strength capacity at yiold point of the finally designed members is :-

$$
1.37(D+L+E)-(D+L) \ldots \ldots R_{2}
$$

If, for example, $\mathrm{M}_{\mathrm{D}+\mathrm{L}}=\mathrm{M}_{\mathrm{E}}$ at beam hinge points, then actual seismic strength at beam hinge points in the finally designed member, from relationship $\left(R_{2}\right)$ above,

$$
=\left(1.37 \times 2 \mathrm{M}_{\mathrm{E}}\right)-\mathrm{M}_{\mathrm{E}}=1.74 \mathrm{M}_{\mathrm{E}}
$$

In other words, the actual base shear yield strength would be $1.74 \mathrm{x}$ design base shear.

Assume that the dynamic response spectrum of an earthquake showed that, for the natural period of the structure concerned, a base shear of $0.10 \mathrm{~g}$ combined with a ductility factor of 4 would give a structure which would only just survive the earthquake, without any margin. The designer, using normal procedures, would then design a structure which would have an overall ductility factor of 4 and an actual base shear strength of $1.74 \times 0.109$, which is 0.1749 . The factor of 1.74 is an essential safety measure to take account of various contingencies.

However, if the finally designed structure was then subjected to the same earthquake, it would develop an overall ductility factor of only 2.3 (assuming that the equal deflection rule of section 4 holds approximately) because the actual base shear strength is now 1.74 times the design base shear, and the individual member ductility factors developed would correspond to this much lower figure. If the designer worked out the hinge rotations required from these results, he would be providing for a system which could only develop a ductility factor of 2.30. In other words, he finally designs a structure which has a base shear strength of $0.174 \mathrm{~g}$ and a ductility factor of 2.30 , instead of a base shear strength of 0.1749 combined with a ductility factor of 4 , which is required. His designed structure is equivalent in dynamic resistance to one with a base shear strength of the bare $0.10 \mathrm{~g}$ and a ductility factor of 4. It will barely survive the design earthquake, without any safety margin for material understrength or uncertainty of applied I oading.

Hence it is apparent that, to obtain the required ductility factor, in a structure where seismic plastic hinges are developed in 
232

beams, the dynamic elasto-plastic analysis should be basod on scaling up earthquake records and (Dead + Live Load) all by a factor of 1.37 .

Similar reasoning will show that, where the seismic plastic hinges are developed in columin, all joading for the dynamic analysis should be scalod up by $\frac{1.25}{0.70}=1.79$.

\section{(15) Necessity for Correlation of Earthquake Records with \\ Smoothed Response Curves}

The acceleration response spectra fur earthquake records are fairly irregular curres, with pronounced local lroughs and peaks. If the structure has a priod which is in a local trough of the response curre for the particular earthqualie used, its response in lerms of excursions into the plastic range will correspond to the value of this trough. These values are unrealistically low as a basis for design, because (a) another earthquake is unlikely to have a local trough at exactly the same period, and (b) one cannot guarantee that the finally built structure will hare exactly that period, and the final period may even correspond to an adjacent peak.

Hence the amplitude of the applied earthquake in such a case should be scaled up to that corresponding to the smouthed response curve.

\section{(16) Necessity for Correlation with Loading \\ Code Base Shears}

For longer period buildings it can be seen from Fig. (3) that the response to the $1940 \mathrm{El}$ Centro earthquake, for a ductility factor of 4 , of structures with periods greater than 1.2 secs., is much less than the Zone A coefficients for Public Buildings required by the N.Z. Code. This is because the N.Z. Code provides for some amplification of ground motion for long period buildings due to soil effects. The earthquake applied in the dynamic analysis should also be scaled up, so that its elasto-plastic response at the period concerned is equal to the code base shear, to take account of such effects. Alternately, the designer may be able to use some other procedure to obtain a realistic assessment of the modification of surface response due to soil conditions.

\section{(17) Cumulative Application of Scaling Factors for Dynamic Analysis}

The factors referred to in sections (14) to (16) for scaling up the record of the applied earthquake in dynamic analysis should be applied cumulatively for the various effects described.

\section{(18) Selection of Earthquake Records for Dynamic Analysis}

This is a matter to which the designer must give careful thought and it is one on which the designer will find it most difficult to determine a satisfactory basis for his choice.

He should consider such matters a the distance of his structure from possible epicentres, the nearness of any fault lines, soil conditions in the area and, of course, the previous seismic history of the area. His requirements are not a mathematically exact response to one particular earthquake, but rather an envelope of responses for a variety of possible earthquakes. Any individual peculiarities in the response charactoristics of the earthquakes used should be looked at critically and a decision made as to whether the unusual features should not be modified. Tho relationship between items in the response curves such as relative magnitude of fundamental and higher modes, phase relationships betwoon fundamontal and higher modes at maximum responso and whether fundamental and higher modes reach maximum response anplitudes during tho same cyclo should all be examined by tho designer.

\section{(19) Design of Frame Structures for Ductility}

There is not sufficiont space lort lo go into the actual design of mombers to provide the required ductility, so the writer's comments must be confined to genoral principles. Most of the codes for design of ductile moment resisting frames are based on the 1966 SEAOC Lateral Force Requirements, or modifications of these. A previous paper by the writer(?) draws attention to features of such methods which appear to require further consideration. It is emphasized again that the SEAOC method assumes that one starts off with a structure in which the $\phi_{u}$ values of the various hinges are $\overline{\phi_{y}}$

moderate, due to favourable balance between member strengths and favourable ratios of column stiffness to beam stifrness, as explained in sections (8) to (10) of this present paper.

It is also emphasized that the SEAOC precedures visualize only beam hinges forming. The columns are given a moderate hinging capacity adjacent to joints to allow for accidental column hinge formation. This is to cover the effects of stiff wall panels or stairs which may have effects of locally stiffening floors or stories that have been overlooked, or possibly even the effects of changes in direction of storey shear for higher modes of vibration. These should involve only small values of $\phi_{u}$ unless the designer has been grossly $\frac{\mathrm{\phi}}{\mathrm{y}}$ negligent in incorporating major features of irregularity into the structure. However, most buildings contain a small number of column hinges which are inherent in the fundamental action of the building - usually at the bottom of the bottom storey columns, as shown in Fig. 6(a). These will involve larger values of $\phi_{u}$ and the comments made in sections (11)

$$
\frac{\phi_{y}}{y}
$$

and (12) of the present paper should be considered in dealing with these. These hinges should be treated on a different basis from the accidental hinges, because their rotation conditions are more severe, the designer is certain that they will develop, they are few in number and thejr positions are definitely known. Also, they occur at the most heavily loaded parts of the columns. The expense of special details with welded fabrication of confining oponents is justified for these conditions. Suggestions for such details are given in the writer's earlier paper $(7)$.

\section{References}

(1) Blume, Jo A., Newmark, N. M., and Corning, L. H. (1961): "Design of Multistorey Reinforced Concrete Buildings for Earth- 
quake Motions". Portland Cement Association, U.S.A.

(2) Baker, A.L.L. and Amarakone, A.M.N. (1964) "Inelastic Hyperstatic Frames Analysis"。 Proceedings of the International Symposium on the Flexural Mechanics of Reinforced Concrete, 85-136. A.S.C.E.-A.C.I.

(3) Corley, W. G. (1966): "Rotational Capacity of Reinforced Concrete Beams". Journal of the Structural Division, A.S.C.E. 92(ST5) $121-146$.

(4) Mattock, A. H. (1967): Discussion on reference (3). Journal of the Structural Division, A.S.C.E., 93(ST2) 519-522.

(5) Hanson, N. W. and Connor H. W. (1967): "Seismic Resistance of Reinforced Concrete Beam-Column Joints"。 Journal of the Structural Division, A.S.C.E., 93(ST 5) 533- 560 .

(6) Park, R. (1968): "Ductility of Reinforced Concrete Frames Under Seismic Loading". N.Z. Engineering, 23(11) 427-435.

(7) McKenzie G.H.F. (1969): "A Critical Look at the Design of Reinforced Concrete for Ductility." Bull. of the N.Z. Society for Earthquake Engineering. 2 (3) 295-307. 